\title{
Terapkan Perilaku Hidup Bersih dan Sehat dengan Optimalkan Cuci Tangan dalam Upaya Pengendalian Infeksi
}

\author{
Nurwinda Saputri \\ Program Studi D III Kebidanan, Fakultas Kesehatan, Universitas Muhammadiyah Pringsewu \\ nurwindasaputri17@gmail.com
}

\begin{abstract}
ABSTRAK
Kebersihan diri adalah sebuah upaya setiap individu dalam memelihara kebersihan diri sendiri yang meliputi kebersihan rambut, gigi dan mulut, mata, telinga, kuku, kulit, dan tangan. Pemeliharaan kebersihan diri sangat menentukan status kesehatan seseorang, karena setiap individu harus secara sadar dan atas inisiatif pribadi menjaga kesehatan dan mencegah terjadinya penyakit agar tidak enularkan atau tertular. Pengetahuan kebersihan diri sangat dibutuhkan oleh setiap individu dalam mempertahankan kebiasaan hidup yang sesuai dengan kesehatan dan akan menciptakan kesejahteraan serta kesehatan yang optimal, dengan setiap inndividu melakukan perawatan kesehatan diri, maka akan memperkecil terkena infeksi. Tempat - tempat Sekolah merupakan salah satu tempat pendidikan yang umum digunakan oleh setiap orang. Cuci tangan adalah merupakan sebuah program pengendalian infeksi, oleh sebab itu pihak Pelayanan Kesehatan setiap tamu, pasien ataupun petugas kita menggalakan untuk mencuci tangan sebalum bersentuhan. Hal ini berguna untuk menghindari penyebaran penyakit ke diri sendiri maupun orang lain. Dikarenakan 98 persen penyebaran kuman di tubuh bersumber dari tangan. Anak usia sekolah baik tingkat prasekolah, sekolah dasar, sekolah menengah pertama, dan sekolah menengah atas adalah suatu masa usia anak yang sangat berbeda dengan usia dewasa, sehingga penerapan kebersihan pada diri sendiri belum sadar akan pentingnya cuci tangan dibandingan dengan orang dewasa. Sehinga sasaran pada pengabdian masyarakat ini adalah anak - anak pra sekolah atau sekolah.
\end{abstract}

Kata Kunci : Prilaku Hidup Bersih dan Sehat, Anak, Cuci Tangan

\begin{abstract}
Self-hygiene is an attempt by individuals in maintaining self-hygiene which include hygiene of hair, teeth and mouth, eyes, ears, nails, skin, and hands. Maintenance of self-hygiene determines a person's health status, as each individual must be consciously and on a personal initiative to maintain health and prevent disease from being transmitted or infected. Knowledge of self-hygiene is needed by each individual in maintaining a healthy living habits and will create a well-being and optimal health, with every inndividu doing health care, it will minimize infection. The places of the school are one of the most common educational places used by everyone. Hand washing is an infectious control program, therefore, the health service of each guest, the patient or the officer we are going to wash the hand of the sebalum in contact. It is useful to avoid spreading the disease to yourself or others. Because 98 percent spread of germs in the body is sourced from hands. School-age children of preschool, elementary school, junior high school, and high school are the age of children who are very different from the age of adulthood, so the application of hygiene on oneself has not been aware of the importance of handwashing compared with adults. As a target to this community devotion is a preschool or school child.
\end{abstract}

Keywords : Clean and healthy living attitude, kids, hand washing

\section{http://ejournal.urindo.ac.id/index.php/PAMAS}

Article History :

Submitted 23 April 2020, Accepted 26 April 2020, Published 29 April 2020 


\section{Jurnal Pelayanan dan Pengabdian Masyarakat (PAMAS)}

\section{PENDAHULUAN}

Sehat adalah merupakan sebuah karunia Tuhan yang perlu disyukuri, dikarenakan sehat merupakan hak asasi setiap individu yang harus dihargai. Sehat juga investasi untuk meningkatkan produktivitas kerja guna meningkatkan kesejahteraan keluarga. Dalam menjaga kesehatan tubuh, memelihara kebersihan tangan merupakan hal yang sangat penting. Dalam aktivitas sehari-hari tangan seringkali terkontaminasi dengan mikroba, sehingga tangan dapat menjadi perantara masuknya mikroba ke dalam tubuh. Salah satu cara yang paling sederhana dan paling umum dilakukan untuk menjaga kebersihan tangan adalah dengan mencuci tangan menggunakan sabun. Di Indonesia penyakit cacingan tersebar luas di pedesaan dan di perkotaan dengan prevalensi semua umur 40\%-60\% dan murid SD 60-80\%. Survei Depkes RI di 10 propinsi di Indonesia menemukan prevalensi kecacingan di Kabupaten Pesisir Selatan tahun 2003 (85, 8\%) dan tahun 2005 (51,4\%) lebih tinggi dari kabupaten lain.

Salah satu upaya efektif menjaga kebersihan adalah dengan mencuci tangan. Manfaat mencuci tangan ada banyak. Badan kesehatan dunia (WHO) juga menyatakan bahwa kedua tangan kita merupakan jalur utama masuknya kuman penyakit ke dalam tubuh. Itu sebabnya, selain menjalankan gaya hidup sehat, kebiasaan mencuci tangan dengan sabun akan mengurangi dan mencegah timbulnya penyakit. Banyak manfaat mencuci tangan yang sayang jika kita abaikan. Cuci tangan adalah proses membuang kotoran dan debu secara mekanis dari kulit kedua belah tangan dengan memakai sabun dan air. Tujuannya adalah untuk menghilangkan kotoran dan debu secara mekanis dari permukaan kulit dan mengurangi jumlah mikroorganisme sementara (Dahlan dan Umrah, 2013). Cuci tangan merupakan salah satu cara untuk menghindari penyakit yang ditularkan melalui makanan. Kebiasaan mencuci tangan secara teratur perlu dilatih pada anak. Jika sudah terbiasa mencuci tangan sehabis bermain atau ketika akan makan ,aka diharapkan kebiasaan tersebut akan terbawa sampai tua (Samsuridjal, 2009).

Badan Kesehatan Dunia (WHO) setiap tahunnya ada 100.000 anak di Indonesia meninggal akibat diare. Untuk itu kami melakukan penyuluhan di Posyandu mentari Pringsewu utara tentang Perilaku Hidup Bersih dan Sehat, khususnya 4 perilaku mencuci tangan pakai sabun di rumah maupun di sekolah. Anak-anak yang kami suluh adalah anak-anak usia 6 tahun - 12 tahun, supaya semua anak bisa lebih mengetahui tentang perilaku hidup bersih dan sehat serta paham mengapa harus mencuci tangan pakai sabun. Pelaksanaan kegiatan ini dilakukan dengan tahap sosialisasi berupa penyuluhan pentingnya Perilaku Hidup Bersih dan Sehat serta mencuci tangan pakai sabun guna meningkatkan kesadaran para siswa tentang kesehatan diri. 


\section{Jurnal Pelayanan dan Pengabdian Masyarakat (PAMAS)}

\section{METODE}

Penggunaan Metode ceramah dan demonstrasi, memberikan pengetahuan pentinngya menjaga kebersihan terutama manfaat cuci tangan, pendampingan anak - anak untuk dapat melakukan cara cuci tangan yang baik dan benar dengan 6 langkah Cuci Tangan menurut WHO. Pada tahapan perencanaan Kegiatan ini dimulai dari dengan melakukan prasurvey tempat untuk pelaksanaan kegiatan, menetapkan sasaran yaitu anak - anak pra sekolah maupun sekolah. Kemudian melakukan pembuatan proposal dan pengajuan dana $70 \%$ untuk kelancaran proses kegiatan, melakukan penyelesaian perizinan tempat/lokasi yang akan dilakukan kegiatan pengabdian pada masyarakat. Pada kegiatan selanjutnya yang sudah ditentukan waktunya, pada tahap ini pengabdi berkoordinasi dengan Pihak Posyandu Mentari Pringsewu, maka Selanjutnya pengabdi mempersiapkan kegiatan penyuluhan berupa materi tentang perilaku hidup bersih dan sehat dengan media yang digunakan (leaflet) dan mendemonstrasikan bagaimana cara cuci tangan yang baik dan benar menurut WHO atau standar kesehatan. Pada tahap pelaksanaan ini dilakukan Pre Test cara anak - anak mencuci tangan sebelum edukasi yang melibatkan semua unsur dalam kegaitan pengabdian masyarakat, kegiatan ini diharapkan bertambahnya peningkatan pengetahuan untuk anak - anak, adapun bahan sebagai pertimbngan perbaikan sikap dan perilaku, maka kegiatan dilakukan sebelum dan sesudah mengetahui cara cuci tangan yang baik dan benar. Sehingga dapat diukur setelah kegiatan selesai, bagaimana peningkatan pengetahuan dan cara cuci tangan yang baik apakah ada peningkatan atau tidak.

\section{Gambar Kegiatan Pengabdian Masyarakat Cuci Tangan}

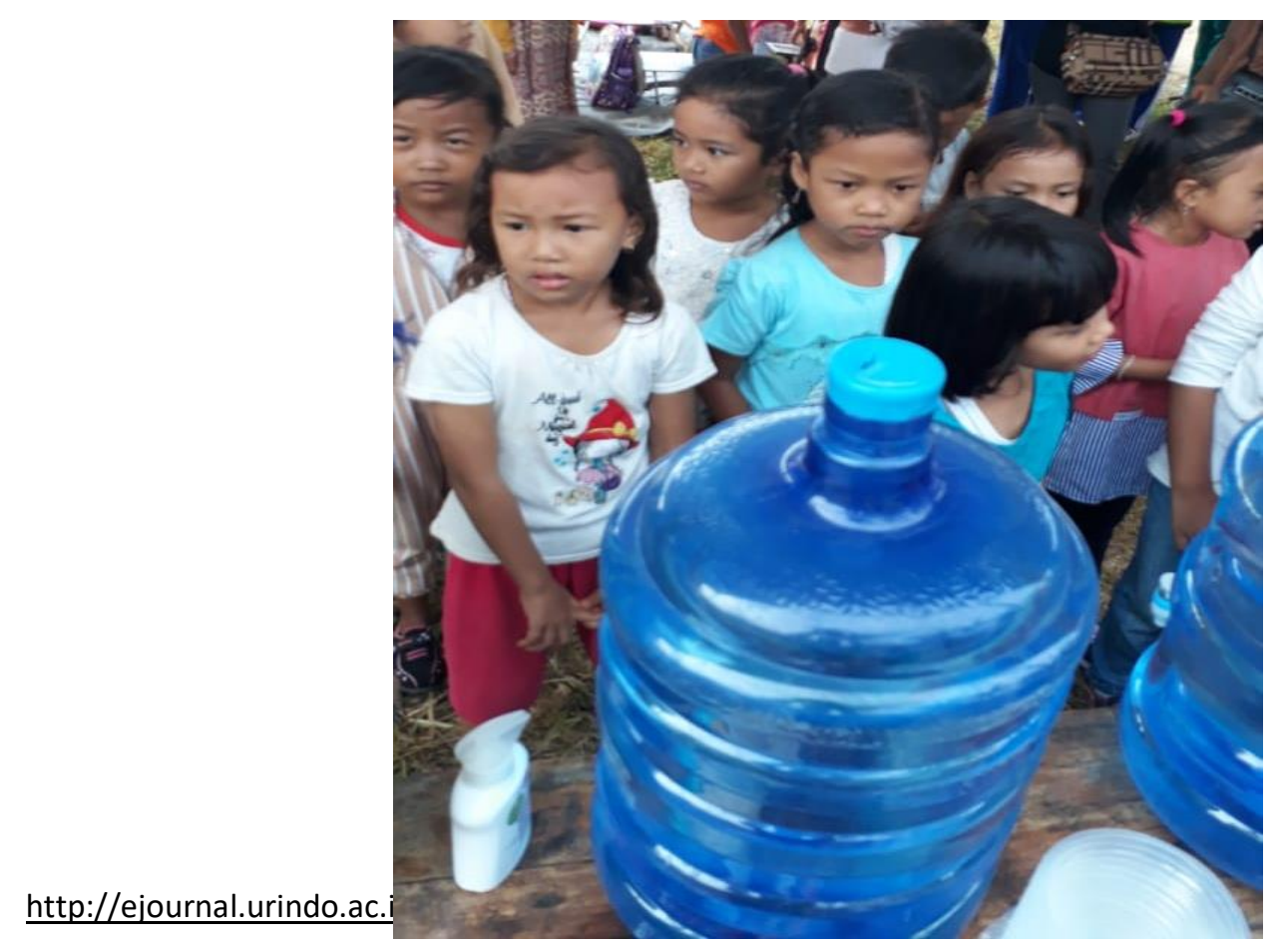




\section{HASIL DAN PEMBAHASAN}

Pelaksanaan kegiatan ini membutuhkan bantuan tenaga para orang tua atau kerabat untuk mendampingi anak - anak dalam melakukan proses cuci tangan dirumah, kegiatan ini membutuhkan waktu 1 bulan untuk merancang, melaksanakan dan mengevaluasi kegiatan yang dilaksanakan. Beberapa hal yang perlu dibahas dalam hasil pengabdian ini, yaitu motivasi peserta yang semula kurang percaya diri dalam melakukan cuci tangan, dapat dilihat dari anak - anak yang malu. Selanjutnya adalah antusias para peserta setelah mendapatkan materi meningkat, dan mereka mau untuk melakukan cuci tangan yang benar, mereka menyimak materi dengan baik dengan terjadinya tanya jawab antar penceramah dengan anak - anak maupun orang tua yang mendampingi.

Saat kegiatan berlangsung, ada beberapa kendala seperti anak yang sulit untuk mengikuti arahan, namun masalah tersebut dapat diselesaikan dengan mengarahkan anak secara perlahan dan membutuhkan proses perhatian yang menarik untuk anak ikut dalam kegiatan pengabdian masyarakat ini. Menurut penelitian fajar dan siti tahun 2013 mengatakan bahwa cuci tangan dengan ari mengalir sangat efektif mengurangi jumlah kuman ditangan. Menurut asil penelitian Retno Purwandar dkk 2011 perilaku cuci tangan pada anak usia sekolah di Kabupaten Jember pada kategori baik (53,7\%), cukup (41,7 \%) dan kurang baik (4, $6 \%$ ). Sedangkan insidensi diare pada anak usia sekolah di Kabupaten Jember dalam kategori rendah (59,3\%), sedang (37,7\%) dan tinggi (3\%). Hubungan antara perilaku cuci tangan dan insiden diare diperoleh nilai $p=0,000$ yang lebih kecil dari 0,05 dan $r=0,792$, maka secara statistik membuktikan ada hubungan yang signifikan antara perilaku cuci tangan dan insiden diare. Upaya promotif dan preventif dalam rangka meningkatkan derajat kesehatan bangsa dan masyarakat dapat dilakukan dengan penerapan perilaku hidup bersih dan sehat. Kebiasaan mencuci tangan dengan sabun, adalah bagian dari perilaku hidup sehat yang merupakan salah satu dari tiga pilar pembangunan bidang kesehatan yakni perilaku hidup sehat, penciptaan lingkungan yang sehat serta penyediaan layanan kesehatan yang bermutu dan terjangkau oleh semua lapisan masyarakat. Beberapa hasil riset menunjukkan bahwa promosi perilaku cuci tangan, peningkatan kualitas air bersih dan sanitasi lingkungan telah terbukti mengurangi kejadian penyakit gastrointestinal, penyakit pernafasan dan menurunkan absensi murid pada negara berkembang (Chittleborough, Nicholson,Young, Bell \& Campbell, 2013)

\section{SIMPULAN}




\section{Jurnal Pelayanan dan Pengabdian Masyarakat (PAMAS)}

Kegiatan ini berbentuk laporan hasil berupa peningkatan pengetahuan anak - anak terkait bertambahnya keterampilan dalam melakukan Cuci tangan yang benar. Keberhasilan ini dapat dilihat dari :

1. Terjadinya Tanya jawab

2. Adanya respon yang positif terhadap kegiatan ini

3. $90 \%$ peserta mengikuti kegiatan dengan baik.

\section{DAFTAR PUSTAKA}

Chittleborough, C.R., Nicholson, A.L., Young, E., Bell, S \& Campbell, R. (2013). Implementation of an educational intervention improve hand washing in primary schools: process evaluation within a randomized controlled trial. BMC Public Health , 13:757, 2-11

Dahlan, A. K., \& Umrah. (2013). Ajaran Ketrampilan Dasar Praktik Kebidanan. Malang: Inti Media Fajar Ardi Desiyanto, Sitti Nur Djannah . (2013). EFEKTIVITAS MENCUCI TANGAN MENGGUNAKAN CAIRAN PEMBERSIH TANGAN ANTISEPTIK (HAND SANITIZER) TERHADAP JUMLAH ANGKA KUMAN. KESMAS, Vol.7, No.2, September (2013), pp. 55 112 ISSN: 1978-0575

RETNO PURWANDARI, ANISAH ARDIANA, WANTIYAH. (2013) HUBUNGAN ANTARA PERILAKU MENCUCI TANGAN DENGAN INSIDEN DIARE PADA ANAK USIA SEKOLAH DI KABUPATEN JEMBER. JURNAL KEPERAWATAN, ISSN: 2086-3071

Samsuridjal D, (2009). Raih Kembali Kesehatan. Jakarta:PT Kompas Media Nusantara 